\title{
Choanal atresia, bilateral
}

INSERM

\section{Source}

INSERM. (1999). Orphanet: an online rare disease and orphan drug data base. Choanal atresia, bilateral. ORPHA:137920

Bilateral choanal atresia is a congenital anomaly that is usually sporadic (but some familial cases have been reported), is more commonly seen in females than in males (2:1), and where the nose is blocked on both sides by bony or soft tissue formed during embryological development. It is characterized by respiratory distress relieved by crying and rhinorrhea that presents at birth. 